\title{
Uncovering Cinematic Adaptations of James Joyce's The Dead
}

\author{
Pegah Marandi ${ }^{1 *}$, Alireza Anushiravani ${ }^{2}$ \\ ${ }^{1}$ University of Tehran, Kish International Campus, Iran \\ ${ }^{2}$ Shiraz University, Iran \\ Corresponding Author: Pegah Marandi, E-mail: pegah_marandi@ut.ac.ir
}

\section{ARTICLE INFO \\ Article history \\ Received: September 02, 2017 \\ Accepted: October 11, 2017 \\ Published: October 31, 2017 \\ Volume: 5 Issue: 4 \\ Advance access: August 2017}

Conflicts of interest: None

Funding: None

\begin{abstract}
The relationship between literature and film is the subject of plentiful analyses and reflections within the general framework of Comparative Literature. A comparison between a literary work and its adaptations shows how filmmakers adhere to the principles of intertextuality. Exploring various adaptations of James Joyce's The Dead (1914) and comparing them against each other are the main objectives of this research. This study examines how John Huston (1987), Travis Mills and William Ivey Long (2013) adapted James Joyce's The Dead (1914) culturally, geopolitically, and sociologically. This study demonstrated that Huston's adaptation was faithful to Joyce's text in terms of character, costume, culture, and language, whereas Mills and Long's adaptation was not fully loyal to Joyce especially in terms of character and culture. However, Mills and Long have attempted to create a language similar to Joyce's. Further, consciousness and interior thoughts as subtle issues precisely shown in the novel were not illustrated wholly in both adaptations. Huston's creativity was maintained in the last scene, picturing Gabriel's monologue, whereas Mills and Long's creativity was shown in creating new postmodern characters and culture.
\end{abstract}

\author{
Keywords: \\ Adaptation Theories, \\ Cinematic Adaptation, \\ Intermediality, \\ Intertextuality
}

\section{INTRODUCTION}

Our culture has rapidly gone from text-based to image-based and people watch more movies than read books. Therefore, adaptations have gained a momentum prominence in the digitalised era. An adaptation is considered as an interpretation, as a specific and original vision of a literary text, and even if it remains fragmentary, it is valuable since it embeds the book in a system of creative activities and interpersonal communication. Cinematic adaptations compel filmmakers to go through the surface of a written text, to dig into what remains beneath this surface, and to re-create it in an aural, psychological, and visual medium. Further, scrutinising a source text and its filmic adaptations demands considerable scholarship to perceive the extent of their influences on each other. Linda Hutcheon's A Theory of Adaptation (2006) discusses the adaptive process. Hutcheon asserts that all media have an ultimate commonality relating to their role in the course of adaptation, and all genres and media (literature, film, and theatre) reveal information about how adaptation functions. She believes that adaptation refers to both 'a product' and 'a process' of creation and reception. Adaptation as a product is an announced and broad transposition of a specific work. This 'transcoding' can require a shift of medium, or genre, or an alter of frame, and thus context. Adaptation as a process takes possession of another story and filters it through one's own interests, sensibility, and talents. Consequently, adapters are first interpreters and then creators. Hutcheon also considers that neither the product nor the process of adaptation exists in vacuum (40). They all have a context: a time and a place, a society, and a culture. Moreover, adaptations are "palimpsestuous" (Alexander, 78; as cited in Hutcheon, 2006) which indicates that the source text's presence is felt in the target text, shadowing everywhere. When a work is considered as an adaptation, its overt rapport to another work is required. It is what Gérard Genette (1982) would call a text in the "second degree," created and then received in relation to a prior text (p. 89). This is why adaptation studies are so often comparative studies. In addition, "one lesson is that to be second is not to be secondary or inferior; likewise, to be first is not to be originary or authoritative" (Hutcheon, 2006, p. 67), thereupon, adaptations are considered as a prominent art. But, some film critics believe the aesthetic and cultural superiority of the printed word over the film. For example, Pauline Kael, the famous film critic for The New Yorker, wrote in 1976, "if some people would rather see the movie than read the book, this may be a fact of life that we must allow for, but let's not pretend that people get the same things out of both, or that nothing is lost" (p. 29). Although Kael shows great admiration for the art of film through her reviews, she detaches the experience 
of film watching from book reading, showing a clear cultural preference for the more traditional experience. George Bluestone, whose 1957 study, Novels into Film has long been recognised as the starting point for much film adaptation study, separates the experience of reading and watching as passive and active endeavours respectively, clearly favouring the active: "we observe that the word symbols in written language must be translated into images of things, feelings and concepts through the process of thought, where the moving picture comes to us directly through perception, language must be fulfilled through the screen of conceptual apprehension" (p. 130). As the history of film adaptation criticism has developed, many critics have taken a vision that they are condescending from the reading performance to watching performance, to them a 'lesser' art form.

\section{LITERATURE REVIEW}

The adaptations' criticism has existed for as long as adaptations have been born. According to Grobstein (2011), "film adaptations have been on the rise because these adaptations attract a wide population of audience. Film adaptations won about three quarters of the Academy Award in 1927 and have consistently hit the top box office counts" (1). In 1957 George Bluestone wrote his determining and highly influential work Novels into Film. Until then, much of what was written on the topic of adaptation was critical, concerning particular films of particular books, and most of the criticism were based on unquestioned suppositions relevant to the process of novel to film adaptation and theoretically undeveloped expectations related to what could and should be attained in terms of the transferal of a text from one medium to another.

\subsection{Adaptation Study and Cinematography}

Chatman's article (1980) as a comparative analysis of cinema and literature provides pivotal information which can be a great help to researchers in the field of adaptation studies. Ellis (1982) explains the adaptation's process and believes that it is not only the novel that is transformed to another medium rather it is the illusion of the reality that the novel claims to produce. Stam et al. (1992) in 'Language in Cinema' in New Vocabularies in Film Semiotics: Structuralism, Post-structuralism and Beyond discuss the correspondence between film and language. Kaye (1994) questions the possibility of attaining an adequate definition of postmodern performance. This study resembles Haberer (2007) that discusses intertextuality and postmodernism as two amalgamated criteria developing parallel with one another. Modernism and postmodernism have guided adaptation into a new pathway: intermediality and intertextuality. Intermediality and intertextuality are prominent aspects because of exchanging culture among various contexts. O'Regan (1999) proposes that "films circulate across national, language, and community boundaries reaching deep into social space" (p. 262). All the stakeholders such as audiences, critics, and filmmakers perceive, negotiate, and transform this global cinema in various ways. Cinema crosses along the borders, cultures, nations, and heterogeneous linguistics: this is cultural exchange. Manovich (2001) re- marks cinema as a new media on the basis of visual history. He shows that old and new mediums articulate with one another to shape new aesthetics and narrative modes. Cardwell (2002) explains what adaptation is and what an adaptation is. She then illustrates the former, traditionally, as the process by which an adaptation comes into being and the latter as a text which adapts another text. Casetti (2004) declares that cinema is aiming to be 'valorised' both as an art form and object of inquiry. It tries to gain artistic value, a privilege which other disciplines such as literature have had for a long time. Kellner (2004) discusses the fact that film emerged as one of the first mass-produced forms of the twentieth-century. In regard to modernisation and technology, new simulations of the real and fantasy world came to being. And film provided a new cultural mode that started to change the patterns of life. Cartmell \& Whelehan (2010) in Screen Adaptation: Impure Cinema raise questions such as what do films tell us about the period in which they are created. How do filmmakers adapt the novels for economic, political, and social purposes? They argued that adaptations can be a field of study which is inter-or perhaps trans - disciplinary, rather than an approach locatable from a number of disciplinary standpoints. Constandinides (2010) points out the digitisation of postmodern era in regard to cinema and film. Furthermore, Cartmell (2012) maintains that up until the middle of the twentieth-century most of the literary critics were opposed to or not on the side of adaptations since they were considered inferior to the source text. However, she 'laments' that some novels are written not just as novels, but as future films (p. 78). Silva (2013) mainly focuses on modern narratives and film adaptations as translations. Moreover, Thomas Leitch's (2017) The Oxford Handbook of Adaptation Studies is the most recent book in which forty essays are gathered discussing different elements of adaptation studies. And in chapter one by Timothy Corrigan three perspectives on adaptation are discussed: process, product, and reception.

\subsection{Early Work: Fidelity}

Much of the earlier works emphasised fidelity as the main constituent in adaptation studies. Fulton (1977) is interested in the differences between the old and new perception of a novel and film. Bortolotti and Hutcheon (2007) compare biology with adaptation studies and believe that adaptation is a kind of replication. Stories are like genes and adaptations are replications and both evolve with environmental change. Connor (2007) emphasises fidelity in adaptations. In chapter five 'Adaptation and Fidelity' of Leitch's The Oxford Handbook of Adaptation Studies (2017), Johnson explains one of the most controversial notions in adaptation studies: fidelity, a word that has been almost impossible to displace from our discourse.

\subsection{Intermediality and Intertextuality}

Intermediality and intertextuality are two key concepts within adaptation studies opening up the field more brighter and more comprehensible than ever to its influence and impact in film and cultural agenda. Intermediality refers to the move- 
ment of texts among different mediums and illustrates how ideas, social and cultural beliefs, and geographical borders alter the source text. Different media are conceived with reference to other media both overtly and covertly since they are principals of broader cultural agendas. Similarly, since adaptation studies require to focus attention on the rapport each text has with other texts, intertextuality comes to the fore. It represents that what is being adapted in any specific case cannot be the text only, nor the essence of the text, but rather a certain understanding of the text that is dialogised, or constantly negotiated along its boundaries. This issue is precisely conceived when Joyce's text is adapted in different time and cultural agendas. Accordingly, Kristeva's (1980) notion of intertextuality began by evoking on the social and political context of the 1960s. She believes that any text is an amalgam of others, a part of a larger fabric of cultural discourse. Aragay (2005) believes that intertextuality presents the original/copy binary pair at the basis of traditional adaptation studies. Scholz's (2009) article maintains that any approach formulated from traditional to modern, ranges from fidelity to intertextuality respectively. Petho (2010) describes intermediality in films and discusses that intermediality has become a generally accepted term in media studies, whereas in film studies it is still a concept encompassing ambiguity and skepticism. Elleström (2010) presents a theoretical framework which describes the rapport among different mediums: what they have in common, how they are different, and how these differences are bridged over by intermediality. The latest and most current study undergone in regard to intermediality and intertextuality is Thomas Leitch's (2017) The Oxford Handbook of Adaptation Studies in which different critics in different chapters discuss the concept of intertextuality. Dennis Cutchins in chapter four, 'Bakhtin, Intertextuality, and Adaptation,' states that an adaptation is primarily "not a kind of text, but a way of looking at texts. I don't mean this answer to be phenomenological double-talk. Adaptations really are a way of thinking about texts, and any structural definition of an adaptation is likely to be problematic" (p. 22). Traditional notion discarded the rapport between the source text and other texts and overlooked the relation between different mediums. But, adaptations re-created today consider the interconnectedness influencing the rapport among different texts and mediums.

\subsection{John Huston's and Travis Mills and William Ivey Long's Adaptations}

Shout's (1989) article demonstrates Huston's life span from the viewpoint of his son, Tony Huston. Barolsky (1989) emphasises the importance of music in Joyce's novella, The Dead. Pederson's article (1993) reveals how Huston has adapted his film from Joyce. She states that "the most intriguing invention of this adaptation is $\mathrm{Mr}$ Grace and his recitation" (p. 69). Olsen (1999) also defines Huston's process of adaptation. Corseuil (2001) explains the rapport between the description and focalization in Huston's adaptation and compares it to the source text. Gronstad's paper (2002) maintains that adaptations of Joyce's fiction are few and only a handful of adaptations of Joyce exist. Other researches such as Luke
Gibbons (2002), Irving Singer (2004), and Eric Paul Meljac (2009) all focus on Huston's adaptive piece. The most recent research in relation to Huston's adaptation refers to Meyers (2011) which pictures Huston's life span and how he became a famous director.

On the other hand, Travis Mills, an American storyteller and filmmaker, and William Ivey Long, an American costume designer, adopted and adapted Joyce's The Dead into a completely new postmodern venue. Postmodernism is specified to a stretch of time in which the rapid arrival of technology and ever increasing cultural multiplicity must encounter with new methods of representation. Postmodernism rejects authority and hierarchy and that is why neither literature, nor adaptation is preferred to one another. Thus, an adaptation being born in this period is quite different in comparison to previous age, like Huston's age, the 1970s. The best book which guided the researcher to elicit good information in relation to postmodernism in America was Adaptation Theory and Criticism: Postmodern Literature and Cinema in the USA (2014) by Gorden E. Slethaug which pictures a number of key terms gleaned from literary theorists of the postmodern including intertextual doubling. Moreover, the researcher did not find any such study including postmodern adaptation and despite the many studies on the literary text and its many forms of adaptations, it seems no such study has been carried out on postmodern adaptations so far especially in regard to Mills and Long's adaptation.

\section{RESEARCH DESIGN AND METHODS}

Comparison and contrast have become crucial methodologies for research. Comparative Literature may as well be performed on works of the same language if the works originate from different time span among which that language is spoken. Moreover, the justification for selecting five particular theorists and applying their theories to Huston's, Mills and Long's adaptations is because their theories illuminate new insight into different aspects of the present case studies. George Bluestone systematises his debate under three sectors contrasting the main characteristics between the mediums of literature and film: one, linguistic and image; two, consciousness and inner thoughts; and three, representation of women. Robert Stam mainly focuses on psychology as a main constituent in adaptation. Linda Hutcheon principally emphasises on 'wh' questions (what, who, why, how, where, and when). Further, the writer will apply Kamilla Elliott's concepts: the psychic model and the ventriloquist model. And finally based on Thomas Leitch's article 'Twelve Fallacies in Contemporary Adaptation Theory' (2003), the writer intends to apply two of his theories: the differences among literary and cinematic texts rooted in essential properties of their respective media; and the conception that literary texts are verbal whereas films are visual. These theorists are chosen chronologically to clarify and to present how the process of adaptation is changed from the old times to recent times, from George Bluestone (1957) to Thomas Leitch (2017).

Bluestone firstly believes that whereas novels are predominantly linguistic films encounter images as main fea- 
ture and thereupon he refers to the presentation of language within these mediums. Secondly, consciousness and inner thought are referred to. And finally, the representation of women is scrutinised within these two mediums. Then, Stam discusses the concept of psychology as a major constituent and Christian Metz and Sigmund Freudian psychoanalysis are discussed within this area too. Having been an advocate of semiotics, Metz's The Imaginary Signifier: Psychoanalysis and the Cinema (1977) was his first psychoanalytical approach to cinema studies. Freudian psychoanalysis written by Freud and later contributed to by Jacques Lacan had been applied to cinema theory previous to Metz. Next, Hutcheon discusses 'wh' questions: 'what' refers to forms (telling and showing) where Hutcheon gives a thorough description of how adaptation operates on different forms of media. 'Who' and 'why' refer to adapters and their personal motives respectively. 'How' refers to the audiences/watchers, the pleasures of adaptation, and modes of engagement. Finally 'where' and 'when' (contexts) refer to transcultural and indigenization. Still, Elliott's famous book Rethinking the Novel/Film Debate (2003) theorises the whole notion of adaptation. The writer will apply Elliott's concepts discussed in chapter five, 'Literary Cinema and the Form/Content Debate,' which begins with the basic heresies of adaptation studies. She portrays six concepts of adaptation, and as she does so, the circular logic of aesthetic theory and practise pays off. Among these categories, John Huston's and Travis Mills and Willliam Ivey Long's adaptations fit into the psychic and ventriloquist categories respectively. And finally, two of Thomas Leitch's theories according to 'Twelve Fallacies in Contemporary Adaptation Theory’ (2003) are applied.

\section{ADAPTIVE THEORIES' APPLICATION AND ANALYSIS}

\subsection{James Joyce and The Dead (1914)}

Joyce's literary works are credibly the most argued, admired, and studied of all modern classics. The Dead was initially published as the final story of Joyce's 1914 collection Dubliners, which portrays stories viewing Dublin life in the early twentieth-century. It is considered a novella rather than a short story since it is under 16,000 words. The story centers on the night of Julia and Kate Morkan's annually dance and dinner party, this particular party taking place in January 1904, on a snowy night. Attending the party is their nephew Gabriel Conroy, a commonly and socially awkward man who would rather be taking a walk alone than spending the night at the dance. The night moves along with much concern for Gabriel. He often becomes anxious, hesitates through conversations, and upsets some other guests. Lastly, Gabriel prepares to leave the party and he and his wife return to their hotel room where he realises that she has become reflective after hearing a familiar song at the party - a song that reminds her of a boy she used to love, who died because of her outside the window in the cold. This relates to Joyce's own life, his relationship to his wife, Nora. Nora was a Galway lady (alike Mrs Conroy) — and had a love affair back in her youth - where a young man stood outside her window in the cold and died later.

\subsection{George Bluestone's Theory Applied to John Huston}

While a novel is principally a linguistic media, a film encompasses images as main facet. One of Huston's noticeable strengths of work is his attention to dialogue. The skill of adapting a literary text is that the details are filled in already: the films are supposed to have texture. This film adaptation by Huston's son, Tony Huston, is considered a close adaptation of Joyce's novella, just with some modifications made to the dialogue to sustain the narrative for cinema watchers. Joyce's narrative embarks on in the core and heart of the action, the focus and standpoint being placed on Lily the caretaker's daughter being "literally run off her feet" (Joyce, 1990 , p. 149), while Huston starts the narrative totally outside of the action, illustrating an image of Gabriel's aunts' house from the outside looking in. It seems likely that Huston exploits this as a method of supplying the film with a location and specifying the location and year where the events are taking place (Dublin, 1904). The text is limited to few details in a sentence, while a film can show many images just in one scene and the watcher can remain more imaginative. Film narrative and language encompasses a plenitude of visual details, and an excessive particularity, but it does not allow the watcher a time to dwell on plenteous details: films show rather than tell. In terms of language, the adaptation stays loyal almost word for word to Joyce's The Dead. For instance, the term 'screwed' meaning 'drunk' was altered to 'stewed' due to its sexual connotations, as was the word 'gay' to 'fine' in the song "For he's a jolly gay fellow," most likely as a result of its modern day use to mean homosexual.

Secondly, characters' mind and consciousness especially Gabriel's and the self-interested depiction in the film are different in comparison to Joyce's and that is inevitable since the novella has more room for description and hammering different scenes and thoughts into the readers' mind than the film. Nevertheless, Gabriel's re-action to his wife's revelation about the dead boy whom she believes has died from her love is depicted in the film as a disintegrated narrative which allows his consciousness to burst just in the end, as a mind detached from the rest of the film. In the final scenes in the novella, his re-action to his wife's heartbreaking exposures might be more plainly read as the disappointment of her failure to recognise his poetic, self-projections. Once again he becomes his own audience. Joyce writes, "generous tears filled Gabriel's eyes. He had never felt like that himself towards any woman, but he knew that such a feeling must be love" (p. 191). According to Chatman (1980), film study and its literary story reveal with major clarity the idiosyncratic powers of these two mediums. As long as distinctiveness is grasped, the reasons for the differences in content, form, and impact of the two mediums come out. As a result, Gabriel's omission of egocentricity thoughts is because of Huston's lack of focalization and to facilitate this, Huston had to incorporate flashbacks or offer a constant voice-over, a fact which supports the argument that Joyce's The Dead is so rich in its own medium that it challenges translation into 
film without serious cuts and simplifications. Nonetheless, neither versions offer any of Gretta's inner motivation. The watcher only retains her spoken words and actions to establish her interior world. Readers are not privy to her viewpoint in the way that they are to Gabriel's.

Finally, Huston explains The Dead as a story on the subject of a man being exposed to him, a statement which, though not incorrect, sheds a shadow over the role of women in the story and, it could be maintained from a feminist viewpoint, the endless struggle between masculinity and feminism. It seems likely that the novella is reasonably fast paced, its description helping the narrative move forward, whereas the adaptation moves at a relatively slow speed, lacking focalization of the descriptive passages by a given character. In both the literary text and adaptation, Gabriel is revealed as a fundamental character and his arrival is enthusiastically awaited by his aunts. Gretta, on the other hand, stays in the background during most of the story, her significance to the narrative not becoming perceptible until the last few pages, adding a part of surprise to her final exposure. It shows how women are illustrated in the second level in comparison to men. In Huston's adaptation, nevertheless, Gretta's importance is noticeable through the casting of the stylish, statuesque, and famous actress Angelica Huston. In what has come to be known as the "staircase scene" (Joyce, 1990, p. 181), Anjelica Huston is standing on the stairs listening to The Lass of Aughrim in an image bring to mind the Virgin Mary, a portrayal supported by the shawl she is wearing around her head, the light creating an atmosphere around her, and the stained glass window she is standing in front of.

\subsection{George Bluestone's Theory Applied to Travis Mills and William Ivey Long}

This 27 minutes adaptation attempts to picture 1900s in a postmodern frame. The Dead (2013) written and directed by honored contemporary screenwriter Mills and Long, foregrounds the concept of creative film authorship. The adaptation is considered a postmodern film, in its intertextuality, deconstruction of subject and the filmic structure, the old traditional (Irish culture) theme, and the oppositional characterisation. T. S. Eliot (1919) asserts that a work of art takes in two components - it is at once personal and also universal. It is an individual constitute, but at the same time, its placing into tradition ascertains its worth and universal appeal. A writer must be conscious that he fits into a larger tradition and there is always an effect of tradition on him. Individual is a constituent formed by and forming the culture to which he belongs. Thus, Mills and Long have completely crossed out the concept of fidelity since it does not fit into postmodernism. According to Kilbourn and Faubert (2014), adaptation studies recently has appeared as a field of critical scholarly significance and, having moved past old-fashioned assumptions and prejudices, has revealed adaptation as a ultimate form of dialogue among different mediums, texts, and social-historical contexts.

Mills and Long's The Dead is a categorisation of argument that transmits the ideas and themes of postmodernism throughout the medium of cinema. The adaptation attempts to challenge the mainstream principles of narrative structure and classification and tests the watcher's notion. Naturally, this adaptation breaks down the cultural isolation among high and low art and often turns over classic depictions of gender, race, and time with the object of generating something that does not bear traditional narrative and structure. Consequently, Mills and Long's adaptation is not aligned with Bluestone's theory since his theory belongs to 1950 s in which both mediums are respected and each of them follows specific structures. For instance in The Dead (2013), when Gabriel asks Lily why you do not marry and in return Lily responds, "no men worth marrying," shows the simple language the filmmakers have composed to the character in comparison to Joyce. In the novella it is shown that Gabriel has a moment with Lily, who he has watched grow up and who is removing his galoshes where he makes it clear that he has observed her growing adulthood-“I suppose we'll be going to your wedding one of these fine days with your young man, eh?" and she replies "the men that is now is only all palaver and what they can get out of you," a bitter assessment of male duplicity that apparently includes him, which causes him to blush (p. 151). This short episode illustrates him to be a man who has a sexual appetite, albeit he would prefer to think of himself otherwise.

On the basis of self-centered/egocentric portrayal; Gabriel's lack of compassion is portrayed in Mills and Long's adaptation. It seems that Gabriel's response to his wife's past love story revelations is elaborated more in the source text than the adaptation. This outbreak of empathy comes rather from Gretta's denial of Gabriel's passion and he becomes frustrated by her falling asleep. He romanticises his feelings, yet again turning his emotional state into an artistic/romantic opportunity to write his own eulogy. In the final scenes in the novella, his re-action to his wife's tragic revelations might be more clearly read as the disappointment of her failure to recognise his poetic, erotic self-projections.

Mills and Long's adaptation is not faithful at all particularly when it comes to the subject of masculinity and feminism: especially Gabriel. The omission of focalization on Gabriel's character and of his interior monologue and consciousness means the watcher does not have the opportunity to comprehend Gabriel's character completely with the inference that women become of extreme less importance to the narrative than in Joyce's source text. Even the last impressing scene was pictured completely different in comparison to Joyce's and Huston's: no monologue and voice-over were shown and not even Gretta's falling asleep. Many of Joyce's delicate scenes and themes become less vague and even omitted in Mills and Long's adaptation such as when the aunts' non-conformist lifestyle are overlooked and discarded. Indeed, no filmmaker is expected to deliver the depth inherent in the literature of one of the most cerebral of all writers. In postmodern adaptations not all details are conveyed due to various reasons which intermediality and intertextuality stands at the centre.

\subsection{Robert Stam's Theory Applied to John Huston}

Metz's The Imaginary Signifier: Psychoanalysis and the Cinema (1977), book on psychology, is concerned why watchers 
choose to watch a film. Regarding the desire for ego, it tries to fulfill senses since cinema is conceived through both sight and sound and it is a collection of images and sounds that stimulate and are read by more senses than most other art forms. In Huston's adaptation several love stories are depicted, but none of the characters, the watchers learn, have been cut so deep as Gretta. Watchers' unconscious try to analyse all these information and complete the open-ended scenes particularly the last scene where Gretta moans herself to sleep and Gabriel stands at the window to watch the falling snow. He recognises that the kind of love Furey felt is not something he knows, and rebukes himself for his reason and cautiousness. He thinks of his Aunt Julia's failure, and how "one by one we're all becoming shades" (Joyce, 1990, p. 191). The snow that is "general all over Ireland" (Joyce, 1990, p. 192) and which he watches falling, supplies a kind of imagistic resolution. As snow falls "on all the living and the dead," (Joyce, 1990, p. 192) Gabriel accepts his death, and that the solid world itself is ephemeral, diminishing, and dissipating. This particular scene both in the novella and the film is left open for readers and watchers to resolve it in their unconscious.

\subsection{Robert Stam's Theory Applied to Travis Mills and William Ivey Long}

Concerning the psychoanalysis, cinema, and film, in Mills and Long's adaptation not much is shown in relation to psychoanalysis and characters' mind. Specifically, in this adaptation, in the scenes in which Gabriel functions as a filter, he is not shown as a sympathetic character. He is a detached figure who is only anxious with his own speech for he is shown as being completely insensitive to the characters surrounding him. There is basically no assimilation between Gabriel and the other characters, as the camera is constantly showing him in his attempt to glance at his speech. Thus, it seems Joyce attempted to show Gabriel's mind and how readers can identify with him whereas in this adaptation nothing is shown. In both the source text and the adaptation, Gabriel's actions are unbearable such as when he delivers a bad and condescending speech, he objectifies the maid, he fights with another woman, and he ignores and disrespects his wife.

\subsection{Linda Hutcheon's Theory Applied to John Huston}

Regarding 'what' the relations between telling and showing in proportion to media specificity is depicted. Hutcheon endows her attention to the features of performance, especially interpretations including dialogue, gesture, and the voiceareas of media studies that have often been disregarded in the past: Bluestone's era. Huston and his elder son, Tony, who did the very much faithful adaptation, discovered the rich narrative line that built to the film's big, breathtaking coda. Similar to Joyce's story, the adaptation reveals itself with gentle caution in bits of observed behaviour and overheard conversation, which originally seem as unreasonable as Molly Ivors' criticism of Gabriel: an assertive young woman, Molly Ivors, mocks the hostesses' nephew, Gabriel, for being a "West Briton" (Joyce, 1990, p. 160) who neglects
Irish culture. And Aunt Kate carefully point to the protestant Mr Browne as being "of the other persuasion" (Joyce, 1990, p. 166). The Huston camera moves about the undistinguished, middle-class Morkan drawing room where there is dancing before the dinner, as if it were a guest looking for a place to sit down. It seems to know everyone slightly but no one remarkably well.

Next, regarding 'who' and 'why,' adapters and filmmakers are people who adopt, adapt, and re-create the source text in a new milieu and function within this creative field. Hutcheon (2006) maintains that the reasons behind why adapters re/create adaptations are diverse and can include cultural aspects, economics, reverence, personal interests, social commentary, and sheer entertainment. She asserts "[The reasons behind adaptation] should be considered seriously by adaptation theory, even if this means rethinking the role of intentionality in our critical thinking about art in general" (p. 95). Reasons for creating art are almost as significant as the art itself. Therefore, Huston attempted to re-create Joyce's masterpiece in a new era to enliven Joyce, his novella, and because of economic matters.

By 'how,' Hutcheon (2006) refers to the audience and modes of engagement. Hutcheon concentrates on the way these media engage their audiences and takes these modes of engagement as the frame for her theory of adaptation. The way Huston adapts Joyce's text is quite different in comparison to the original: audiences would feel different, engage differently, and analyse in a different way. As actors sing and dwell on and cast tears while staring into the camera, we are watcher to a film. We are dipped into sequences especially filmic as the camera illustrates and captures the chaos of Gabriel's and Gretta's lives. The actors act and sing in a way which engages the watchers and this is the deceit of the adaptation; they are presenting their thoughts for our benefit. He then introduces the readers up — up — into the aura - and Gabriel looks down on all as though he is already a "shade" (Joyce, 1990, p. 191). And where does Gabriel go? Where does he have to go? "Westward" (Joyce, 1990, p. 192). There is no other direction. "The time had come for him to set out on his journey westward" (Joyce, 1990, p. 192). What a sentence. What an inexplicable sentence. It is as though Gabriel had this date from the start — only he had no alertness of it. But now he knows. And what does he feel? But love. A "swoon" (Joyce, 1990, p. 192) of it. This last scene exclusively was tremendously hard, inflexible, and tricky for Huston to translate and transmit by means of image, sound, and voice. He masterly tried to engage the watchers through the voice-over and monologue used by Gabriel to convey Joyce's message as clearly as possible.

'Where' and 'when' (context) are two components denoting the hypotheses of both indigenization and transcultural. Indigenization and transculturation between cultures and languages vary in which the meanings can alter essentially. Highlighting the idea that "cultures change over time," (Hutcheon, 2006, p. 142), Hutcheon's discussion of transculturation predominantly focuses on the way that "within a single culture, the changes (from source to adaptation) can be so great that they can in fact be considered transcultural 
on a micro-rather than a macro level" (p. 147). She writes, "there is a kind of dialogue between the society in which the works, both the adapted text and the adaptation, are produced and that in which they are received and both are in dialogue with the works themselves" (p. 149). Huston's film does differ in comparison to Joyce's, but still remains faithful.

\subsection{Linda Hutcheon's Theory Applied to Travis Mills and William Ivey Long}

Concerning 'what,' these two filmmakers attempted to alter the form along with the content: Gretta's nationality is changed to Lithuanian which is a crucial change in the form. In postmodern adaptations, different nationalities, languages, and ethnics are observed so the watcher is completely acquainted with this matter. But in Huston's time, the watchers could not accept if a filmmaker changed the nationality of Joyce's character to a new one. Also, the setting is ordinary and encounters minimalism where there is not much furniture around, but in the novella all the furniture are described and expressed as classical and traditional. Also, the costumes and language are modified to postmodernism which points up different cultural issues. 'Who' specifically refers to the adapters in this case Mills and Long, who in collaboration with each other decided to direct this short postmodern adaptation. 'Why' refers to the concepts of economic component, legal constraints within the process, and adapters' personal, political, or social intentions.

In regard to 'how,' Mills and Long try to engage the watchers psychologically into the story by creating characters and circumstances that generate reliability, sympathy, and trouble. In the adaptation Gretta, as a Lithuanian, cannot be involved with the Irish family because of cultural exchange and also it is observed that her real name is Ogna, but she calls herself Gretta in order to vanish the distance amid the cultures. In addition, watchers are appealed to characters who are attractive - who are beautiful, charming, funny, hospitable, powerful, and skilled like Freddy. In regard to 'where' and 'when,' it is important to take into account the time and place when Joyce's novella was composed and the context when Mills and Long adapted that novella. As well as each medium, each era has its own political and societal features. Thus, Joyce's society in terms of religion in 1904 seems to have played a much greater role than in 2013. The 1901 census depicts that the considerable majority of Irish people were assumed Roman Catholics, with a protestant majority only in the north of the country. So, society of that time was quite different in comparison to 2000s and that can be seen in Joyce's novella where it points to societal, religious, and political components: when Miss Ivors and Gabriel argue over Ireland, other countries, and their language, or when aunt Kate and Miss Browne argue over the Pops and the coffins.

\subsection{Kamilla Elliott's Theory Applied to John Huston}

Kamilla Elliott's the psychic model is applied to the adaptation. The psychic model tells that a novel's spirit can migrate into a new body; it is therefore the film's objective to seize this wandering spirit. Huston's adaptation attempts to adhere to the source text and convey and translate almost all the scenes to the film. Huston knew that he is adapting a masterpiece and should ensure that it should prove worthy of Joyce in general and that it should not, in particular, so misrepresent the tone and spirit of the story that Joyce's name could not admirably be associated with. Huston's faithfulness is seen almost in every scene. For instance, life and love on one hand and mortality and the passing of time on the other are frequently allied with music and dance in the film. D'Arcy's singing of The Lass of Aughrim reminds Gretta the dead Michael Furey, who sang the same song. But though the remembered singers are gone, they live again in the memories and emotions of those who heard them sing. Such a concurrently compassionate and objective viewpoint is typical of Huston's cinematic art from the beginning of his career if he learned it from Joyce - as to some extent he might well have done - the lesson would not have come from his late adaptation of The Dead, but from his early, passionate participation with Ulysses and other of Joyce's works.

\subsection{Kamilla Elliott's Theory Applied to Travis Mills and William Ivey Long}

Kamilla Elliott's the ventriloquist model is applied to the adaptation. The ventriloquist model empties the body of the source text of its spiritual content and gives it a new voice. According to Meikle (2013), the filmmakers use the source text as raw material. Bluestone (1957) also states that the filmmaker treats the source text as raw material and eventually re-creates his own unique structure. It seems that the source text and the adaptation can share the same story, the same raw materials, but can be differentiated by means of different plot strategies. In Mills and Long's adaptation, new plot and characters are born. For example in the first scenes of the adaptation, Mr Browne rings the door bell and aunt Julie says "he is not Irish but at least Christian" which is different in comparison to the novella. The psychological aspect is a prominent feature in Joyce's works; whereas in this adaptation no monologue is seen at all and Gabriel's conscious status is omitted completely. Meikle (2013) believes that adaptation is considered as a hierarchical process in which filmmakers and adapters convert crude materials into a more refined one that shed source texts as natural resources and adapters as miners employed in the business of natural resource extraction. Further, Cartmell and Whelehan's The Cambridge Companion to Literature on Screen (2007) discusses that a film can be better than the book it is "based" on and that the film can be the original of the literary text (p. 256). Robert Stam in 'Beyond Fidelity: The Dialogics of Adaptation' (2000) refers to characters which can be modified in the process of adaptation and this issue can be clearly observed in Mills and Long's adaptation. In their adaptation, they try to alter mainly the characters and focalization whereas the view point stays the same: Gabriel's view point. Although Joyce's The Dead is narrated as a nostalgia in the first person by Gabriel, the film is neither narrated in the first person, nor it is a nostalgia, nor it is told from any specific viewpoint except that, perhaps, of the postmodern cinema 
itself. But in Huston's adaptation it is completely different. He has attempted to follow the same characters, theme, plot, and scenes vis-à-vis Joyce's.

\subsection{Thomas Leitch's Theory Applied to John Huston}

In his famous article 'Twelve Fallacies in Contemporary Adaptation Theory' (2003), Thomas Leitch attempts to draw out some fallacies and theories attributed to adaptations. Firstly, Leitch argues against the differences between literary and cinematic texts rooted in necessary properties of their respective media. It seems that Leitch's theory cannot be applied to Huston's adaptation because Huston had to alter some parts due to the differences among the two mediums. Huston seems to believe that he should clarify, or impose his own interpretation on points that Joyce had deliberately left ambiguous. Nevertheless, it would be a mistake to assume Joyce's indecision is a failure on the author's part. If there are open-ended parts in Joyce's text, they are there to support the complexity of the protagonists' behaviour. On the other hand, Huston endeavours to resolve these unresolved narrative passages and attempts to illuminate the text in cinematic terms in the only ways he and his son were able within the medium. For instance, Gabriel's depiction for whom Joyce writes interior thought is complicated because of the nature of film which relies on direct dialogue and on screen action.

Secondly, Leitch argues against the conception that literary texts are verbal whereas films are visual. He believes that this theory is obviously untrue, not because literary texts are not verbal, but because films are not narrowly speaking visual. He states that at least they have not been purely visual for at least seventy-five years. Regarding Huston's film, this is precisely observed since different senses such as sight (vision), hearing (audition), and also the psychological phase are activated and leaves the watchers to interpret differently. Huston attempted to add dance and music to the adaptation to re-liven Joyce's atmosphere. It is a charming and original work that is true enough to the music in Joyce's novella and different enough to give vivid life to its actual musical elements. The music Huston inserted into the script is perfectly attuned to Joyce's mood. As he has replaced and added songs and lyrics to those referred to in the story, he has remained faithful to Joyce's poetic blend of celebration and the melancholy shadow of death, but not slavishly so. To deal with the complex internalised elements of the story, Huston made Gabriel both the narrator and the character. As a narrator, he speaks directly to watchers with the guests either going into a freeze scaffold or at one point smartly continues to act as if the character were still in their middle. These narrated monologues work quite well and strengthen the musical's literary underpinnings.

\subsection{Thomas Leitch's Theory Applied to Travis Mills and William Ivey Long}

Leitch believes that the differences between literature and film are not solely because of dissimilarity, but rather different psychological interpretations are the main reason.
However, Leitch's theory cannot be applied to Mills and Long's adaptation due to the difference in context, time and place, and culture. Plainly, the present writer tends to think that these two mediums are a response to the culture and events of a particular time. Though literature may not be directly affected by another type of artistic movement, both are affected by history. Indeed, when a watcher watches Mills and Long's adaptation, s/he will automatically feels the essence of postmodernism and compares that to Joyce's 1914 context, hence specific themes pop up: the need for the individual to express himself or herself in a gradually more chaotic world, and an experimentation with or even rejection of specific traditional rudiments which is to some extent eliminated within the adaptation. The directors have taken liberties with Joyce's crystalline text, which sometimes works, as when Gabriel narrates part of the story, but sometimes is theatrically overinflated - mainly at the end, when Joyce's language, which itself aspires to music, is plenty lyrical enough. Secondly, regarding the disagreement against the point that texts are verbal whereas films are visual, Mills and Long's adaptation seems to engage watchers' different senses such as sight (vision), hearing (audition), and also their psychological facet is initiated and leaves the watchers to interpret the story in different ways.

\section{CONCLUSION}

As has been examined and probed into different adaptations, it is observable that adaptations of a literary work have played an underlying part in film history since the very beginning of its production. As soon as film realised its potential to convey the literary narrative on screen, literature became the treasure house of ideas for film. James Joyce's The Dead (1914) has been inspired by two filmmakers, John Huston's The Dead (1987) and Travis Mills and William Ivey Long's The Dead (2013). Each of these adaptations is based on five different adaptive theorists: George Bluestone, Robert Stam, Linda Hutcheon, Kamilla Elliott, and Thomas Leitch. The aim of the study was exploiting an adaptive strategy to present how different filmmakers re-created adaptations in new context in West. Adaptation as a medium encounters a thorough creativity which leads to both a gain and a loss. The results highlighted that regarding the five theorists applied to Huston, characters, costumes, cultural rudiments, and language have not been altered very much as comparison to Joyce's, whereas in Mills and Long's adaptation, characters and culture have been modified very much. But, all the filmmakers have attempted to re-create the language as loyal as possible compared to Joyce. Therefore, wherever a feature is lost another is gained. Though Huston's fidelity was observed, his creativity remained where characters' interior thoughts and consciousness were illustrated especially Gabriel's last scene monologue. Mills and Long's creativity was achieved when the filmmakers tried to show new postmodern characters, costume, and culture. Furthermore, Huston's, Mills and Long's adaptations were inspired by the context being generated in and thus conducted new creativity. 


\section{REFERENCES}

Aragay, M. (2005). Books in motion: Adaptation, intertextuality, authorship. NY: Rodopi.

Barolsky, P. (1989). Joyce's distant music. The Virginia Quarterly Review, 65(1), 111-118.

Bluestone, G. (1957). Novels into film. California: University of California Press.

Bortolotti, G. R., \& Hutcheon, L. (2007). On the origin of adaptations: Rethinking fidelity discourse and "success" - biologically. New Literary History, 38, 443-458.

Cardwell, S. (2002). Adaptation revisited: Television and the classic novel. UK: Manchester University Press.

Cartmell, D., \& Whelehan, I. (2007). The Cambridge companion to literature on screen. UK: Cambridge University Press.

Cartmell, D., \& Whelehan, I. (2010). Screen adaptation: Impure cinema. London: Palgrave MacMillan.

Cartmell, D. (2012). A companion to literature, film, and adaptation. USA: Blackwell Publishing Ltd.

Casetti, F. (2004). Adaptation and mis-adaptations: Film, literature, and social discourses. In R. Stam, \& A. Raengo, (Eds.), A companion to literature and film (pp. 81-91). USA: Blackwell Publishing Ltd.

Chatman, S. (1980). What novels can do that films can't (and vice versa). Critical Inquiry, 7(1), 121-140.

Connor, J. D. (2007). The persistence of fidelity. Adaptation Theory, 10(2), 1-5.

Constandinides, C. (2010). From film adaptation to post-celluloid adaptation: Rethinking the transition of popular narratives and characters across old and new media. New York: The Continuum International Publishing Group.

Corrigan, T. (2017). Defining adaptation. In T. Leitch (Ed.), The Oxford handbook of adaptation studies (pp. 1-16). USA: Oxford University Press.

Corseuil, A. R. (2001). John Huston's adaptation of James Joyce's The Dead: The interrelationship between description and focalization. Cadernos de Tradução, 1(7), 67- 79 .

Cutchins, D. Bakhtin, intertextuality, and adaptation. In T. Leitch (Ed.), The Oxford handbook of adaptation studies (pp. 17-36). USA: Oxford University Press.

Elleström, L. (2010). The modalities of media: A model for understanding intermedial relations. Media Borders, Multimodality, and Intermediality (pp. 11-48). UK: Palgrave Macmillan, 2010.

Eliot, T. S. (1919). Tradition and individual talent. The Egoist, 4(VI).

Elliott, K. (2003). Rethinking the novel/film debate. UK: Cambridge University Press.

Ellis, J. (1982). The literary adaptation. Screen, 23, 3-5.

Fulton, A. R. (1977). From novel to film. In J. Harrington (Ed.), Film and/as literature (pp. 151-155). USA: Prentice-Hall.

Genette, G. (1982). Palimpsestes: La littérature au second degré. Paris: Seuil.

Gibbons, L. (2002). The cracked looking glass of cinema: James Joyce, John Huston, and the memory of The
Dead. The Yale Journal of Criticism, 15(1), 127-148.

Grobstein, P. (2011). A citique of the criticism of film adaptations. Retrieved September 25, 2017, from http://serendip.brynmawr.edu/exchange/thebeliever/critique-criticism-film-adaptations.

Gronstad, A. (2002). The gaze of Tiresias: Joyce, Rossellini and the iconology of The Dead. Nordic Journal of English Studies, 1(2), 233- 248.

Haberer, A. (2007). Intertexuality in theory and practice. Literatura, 49(5), 54-67.

Huston, J., \& Huston, T. (Directors). (1987). The Dead (Film). America: Chris Sievernich and Weiland SchulzKeil.

Hutcheon, L. (2006). A theory of adaptation. New York: Routledge.

Johnson, D. T. (2017). Adaptation and fidelity. In T. Leitch (Ed.), The Oxford Handbook of Adaptation Studies (pp. 37-53). USA: Oxford University Press.

Joyce, J. (1990). Dubliners. New York: Bantam Classic.

Kael, P. (1976). Reeling: Film writings, 1972-1975. USA: Little Brown.

Kaye, N. (1994). Postmodernism and performance. London: The MacMillan Press Ltd.

Kellner, D. (2004). Culture industries. In T. Miller, \& R. Stam (Eds.), A companion to film theory (pp. 202-220). USA: Blackwell Publishing Ltd.

Kilbourn, R. J. A., \& Faubert, P. (2014). Introduction: Film adaptation in the post-cinematic era. Journal of Adaptation in Film \& Performance, 7(2), 155-158.

Kristeva, J. (1980). World, dialogue and novel. In L. S. Rudiez, \& Trans. T. Gora (Ed.), Desire in language: A semiotic approach to literature and art (pp. 64-91). New York: Columbia UP.

Leitch, T. (2003). Twelve fallacies in contemporary adaptation theory. Criticism, 45(2), 149-171.

Leitch, T. (2017). The Oxford handbook of adaptation studies. USA: Oxford University Press.

Manovich, L. (2001). The language of new media. Massachusetts: MIT.

Meikle, K. (2013). Rematerializing adaptation theory. Literature/Film Quarterly, 41(3), 174-183.

Meljac, E. P. (2009). Dead silence: James Joyce's The Dead and John Huston's adaptation as aesthetic rivals. Literature/Film Quarterly, 37(4), 295-304.

Metz, C. (1977). The imaginary signifier: Psychoanalysis and the cinema. Translated by C. Britton, A. Williams, B. Brewster, \& A. Guzzetti USA: Indiana University Press.

Meyers, J. (2011). Writing film biography: John Huston. The Antioch Review, 69(1), 86-100.

Mills, T., \& Long, W. I. (Directors). (2013). The Dead (Film). America.

Olsen, V. (1999). On the page/on the screen: Two ways of reading Joyce. English Language and Literature Studies, 9, 99-108.

O’Regan, T. (1999). Cultural exchange. In T. Miller, \& R. Stam (Eds.), A companion to film theory (pp. 262-295). USA: Blackwell Publishing Ltd.

Pederson, A. (1993). Uncovering The Dead: A study of adap- 
tation. Literature/Film Quarterly, 21(1), 69-70.

Petho, A. (2010). Intermediality in film: A historiography of methodologies. Film and Media Studies, 2, 39-72.

Scholz, A. M. (2009). Adaptation as reception: How a transnational analysis of Hollywood films can renew the literature-to-film debates. Amerikastudien/American Studies, 54(4), 657-82.

Shout, J. D. (1989). Joyce at twenty-five Huston at eightyone. The Dead. Literature/Film Quarterly, 17(2), 91-94.

Silva, C. A. V. (2013). Modern narratives and film adaptation as translation. Acta Scientiarum: Language and Culture,
$35(3), 269-274$

Singer, I. (2004). The Dead: Story and film. The Hudson Review, 56(4), 655-665.

Slethaug, G. E. (2014). Adaptation theory and criticism: Postmodern literature and cinema in the USA. London: Bloomsbury.

Stam, R. (2000). Beyond fidelity: The dialogics of adaptation. In J. Naremore (Ed.), Film adaptation (pp. 54-76). London: Athlone.

Stam, R., Burgoyne, R., \& Flitterman-Lewis, S. (1992). New vocabularies in film semiotics: Structuralism, post-structuralism and beyond. London: Routledge. 